\title{
The Challenging Context of Assistive Technology : A View from the USA
}

\author{
Alexandra Enders, OTR/L \\ Rural Institute on Disabilities, \\ The University of Montana, \\ USA
}

\begin{abstract}
Assistive technology presents the need for a new way of thinking about disability services, benefits, and rights. The challenge of public policy development related to technology is to help rekindle the dream of equitable participation in the community, including the workplace. Technology is a powerful tool for access and community integration. The challenge to designers, engineers and practitioners is to technology can help the individual attain.
\end{abstract}

\section{INTRODUCTION}

Assistive technology has an enormous impact on the lives of Americans with disabilities. Though it would be interesting to present to you a few specific examples of the many exciting and successful applications of assistive technology in the U.S., we can probably learn more from each other by highlighting some of the challenging issues raised by the use of and need for assistive technology; and by sharing some of the lessons we are learning. Some of the policy issues are specific to the U.S.A. Others may be universal. For example, I think we can all agree that three are major differences between the numbers of people with disabilities in each of our countries who could benefit from technology, and those who currently have access to it. The reasons may be a little different, but the solutions could have much in common.

In the U.S. we have found that the reason people who need assistive technology do not get it, is only rarely because the technology does not exist. Almost always the problem is found in our capacity and resourcefulness in the delivery of technology related services; in our expectations of who might benefit from assistive technology; and our experience of how technology can be creatively and effectively supplied.

Japan, the U.S.A., and other countries represented at this meeting are all technological societies. Policy develops from the expectations of the majority of society. All of our citizens, whether or not they have disabilities, expect technological solutions. However, technology has been advancing more quickly than resource allocation mechanisms, at least in the U.S.A. We are still learning how to develop disability policy that reflects current technological expectations and capabilities, policy that supports the promises that assistive technology can deliver.

Realty Testing: Understanding the Consumer's Perspective 
REIS'92

When working at the leading edge, we must remember that we are probably only seeing an elite minority of the individuals who could benefit from technology. My friends frequently ask me when they are going to have access to these wonderful advances. It was indeed distressing for me to hear one of the leading disabled activists testify to the U.S. Congress that:"So much of the system is based on excluding us. We need a system that does some form of assessment, then provides us with what has been acknowledged that we need. There is virtually no outreach, no information to the people who need the technology. The professionals are not really acting as advocates or as adversaries, they just do not understand what is available or what it could do for us."

She goes on to say, "We do not know what technology can do for us. We do not know what to ask for. We do not even know we should ask. We do not dream or we have stopped dreaming. Dreams for us are things that the average able bodied person takes completely for granted, e.g. getting up in the morning and taking a shower, taking the bus or going to the office without a lot of preparation. We have to justify that everything we need must either be medically necessary or employment related, as if that were the extent of living. We do not get what we need; if we are lucky, we may get what is getable. Furthermore, there is still a strong medical bias that if we use technology, we are failures."

I do not believe this is an American phenomena. I have heard similar statements from citizens of many other countries. The situation may be a little better or worse, but nowhere is it perfect. The rapid onset of need and the limited time for growth of assistive technology services has provided little historical perspective on the optimum model for this process. There are many local issues that will dictate the method of initiating a consumer responsive service system, and it it imperative that further analysis of these conditions be conducted to determine the common elements that produce high quality, effective results. We must strive for consistency and integrated system which are based on some similar assumptions.

\section{Promoting Consumer-Responsive Systems Change}

In the U.S. Congress Office of Technology Assessment's 1982 report Technology and Handicapped People, the major conclusion reached was that "despite the existence of numerous important problems related to developing technologies, the more serious questions are social ones -- of financing, of conflicting and ill-defined goals, of hesitancy over the demands of distributive justice, and of isolated and uncoordinated programs." The 1987 update reported that the situation was much the same. This led to new federal legislation, the Technology Related Assistance Act of 1988 focused on promoting consumer responsive systems change at the state level. Currently 33 of our 50 states have received grants to implement this approach. It is anticipated that by next year, all of our states and territories will have these systems change projects.

\section{Benefits and Value}

There are existing and budding technology applications to meet needs of people with physical, sensory, and cognitive disabilities. Appropriate technology services reach far beyond the stereotype of wheelchairs for individuals with mobility impairments, custom jigs and fixtures in work settings, or computers in the classroom 
or office. However, regardless of how the people and the technologies are categorized, we must ensure that we avoid an overly restrictive view of who might benefit from the creative application of appropriate technology. Development of the capacity for an integrated technology service delivery system must move beyond limiting notions of which types of technology can provide benefit. In the U.S. and elsewhere, the independent living movement, a growing elderly population, technological opportunities, and younger generations who expect technological solutions to be readily available, are coming together to generate a fertile field for advancing the current state of the art in applied technology.

However it is critically important, especially for those of us working in this field, that we do not get lost in the devices -- in how they look, how much they cost, what they can do. Any focus on the hardware is misdirected. The focus should be on the person, on how the person's ability is augmented. It should not matter that the equipment is a piece of rubber tubing, a high tech composite wheelchair, a robotic work station, or an adapted telephone. The emphasis should be on the self-direction the technology helps the individual attain.

Currently, U.S. public policy has a medically-oriented approach which subtly (and something not so subtly) implies that you are a failure and/or an object of pity if you resort to using assistive technology. Most attention is on technology that can fix people, that can replace body parts rather than augmenting human functional ability. Regulations often define where you can buy the technology, what kind of technology can be bought; it often treats the private sector as rip-off artists seeking to abscond with public funds. There is an underlying attitude that the technology should be used to "fix the poor cripples," rather than as a means for integrating valued community members into society. There are strong restrictions against providing luxury items. Medicare, one of the major funding sources, goes so far as to deny payment for any devices that would be useful to a person who was not sick or injured! We have other systems (e.g. special education and vocational rehabilitation) which use broader interpretation, but even these systems are influenced by the medical model.

\section{Listening to Your Customers}

In the U.S. we sometimes get confused about who our "customers" are. In many cases, assistive technology is paid for by a third party (e.g. a government agency or insurance company), which results in our need to sell these third party payers on the benefits of the technology within a framework they understand. Unfortunately, this framework can be contradictory to the needs expressed by the end-user of the +echnology, i.e. the person with a disability. It is critically important to listen to your real customers, the end-use. Experience has shown me that carefully listening to people with disabilities is the best way to learn how to provide the right assistive technology. Working in an Independent Living Center, where my employers and colleagues were people with disabilities, was the most important influence on my career. I understand that there are several Independent Living Centers in Japan. I urge you to work closely with the people who work at and receive services from these organizations. They will be your best teachers.

\section{DEFINITIONS}


Definitions for key terms may be needed to prevent misunderstanding. In the U.S. we are using new language -- assistive technology -- to describe a broad range of technological support for people with disabilities. The words "assistive technology" include what had previously been called "rehabilitation engineering." Assistive technology is defined in the Technology Related Assistance Act of 1988,. You will also note that RESNA is no longer the Rehabilitation Engineering Society of North America, it is just the letters R-E-S-N-A. Although many of our members are engineers, most are not. But we all work together, however, to develop and deliver assistive technology and related services.

Because there is also considerable confusion about concepts such as independent living and the nature of independence, definitions for these terms are also included. This confusion is deeply embedded in U.S. disability policy which has developed over the past 80 years. This causes programs to be uncoordinated, and to work at crosspurposes. The importance of these differences and assumptions will be discussed later in this paper. Unfortunately, there is no legal or standard definition of independent living to cite. These definitions are taken from leaders in the U.S. independent living/disability rights movement.

Independence: should be defined in terms of how much control an individual with a disability has over his/her environment, not in the number of tasks that can be done without assistance.

Independent living: the basic ongoing support services and systems an individual with a disability needs to live a self-directed life; includes recognition of the role of the person's environment (transport, access, housing, etc.) for economic and community integration.

Assistive technology: defined in the Technology Related Assistance Act of 1988 as:

(1) ASSISTIVE TECHNOLOGY DEVICE. -- The term "assistive technology device" means any item, piece of equipment, or product system, whether acquired commercially off the shelf, modified, or customized, that is used to increase, maintain, or improve functional capabilities of individuals with disabilities.

(2) ASSISTIVE TECHNOLOGY SERVICE -- The term "assistive technology service" means any service that directly assists an individual with a disability in the selection, acquisition, or use of an assistive technology device. Such term includes:

(A) the evaluation of the needs of an individual with a disability, including a functional evaluation of the individual in the individual's customary environment;

(B) purchasing, leasing, or otherwise providing for the acquisition of assistive technology devices by individuals with disabilities;

(C) selecting, designing, fitting, customizing, adapting, applying, maintaining, repairing, or replacing of assistive technology devices;

(D) coordinating and using other therapies, interventions, or services, with assistive technology devices, such as those associated with existing education and rehabilitation plans and program;

(E) training or technical assistance for an individual with disabilities, or, where appropriate, the family of an individual with disabilities; and

(F) training or technical assistance for professionals (including individuals providing education and rehabilitation services), employers, or other individuals who provide services 
to, employ, or are otherwise substantially involved in the major life functions of individuals with disabilities.

\section{PRIMARY DIFFERENCES}

Resource allocation issues are at the root of assistive technology availability in all countries. However you must be aware that in the U.S. there are several public policy essentials that may be quite different than those of most other industrialized nations. People outside the U.S. generally have a difficult time realizing that U.S. policy differs from basic assumption in their countries on these basic issues.

(1) The U.S. does not have a national system of universal access to health care. We do not have socialized medical care. We are under enormous cost-containment pressure, as the U.S. spends more per capita on health care than any other country. (The U.S. spent $\$ 2051$ per capita on health care in 1987, or 28 percent more than Canada which was second with $\$ 1483$. Sweden was next, at $\$ 1233$; then France, $\$ 1105$; West Germany $\$ 1093$; the Netherlands $\$ 1041$; Australia, \$939; Japan, \$915; Italy, \$814; Britain, \$758.)

(2) Some of the most important U.S. disability legislation implicitly defines Independent Living (IL) as essentially an alternative to being vocationally feasible. Many other countries seem to take for granted that IL is the underpinning for community integration and employment. However most U.S. disability policy views IL supports as at best an alternative to being feasibly employed. Few U.S. policies provide for ongoing IL support for employed persons with disabilities.

\section{LESSONS WE ARE LEARNING IN THE U.S.}

\section{The Long Term Nature of Technological Support Services}

Equipment was, and still is, often viewed as a one time event, an attitude that is reflected in the policies of many of the U.S. sources for funding assistive technology. However, a disabled person's need for technological support is usually a life long need. ( You may only need to learn to drive once; but if you need one adapted vehicle, you will probably always require adapted vehicles. If you require a motorized wheelchair, it is not likely you will outgrow that need.) There are significant differences in planning for long term versus short term needs. The rehabilitation system has traditionally focused its attention on shorter term and/or time-limited types of interventions. However there is now an increased recognition of the importance of ongoing, coordinated support systems such as independent living and supported work. Technological support services and systems play an important role in these new trends that are redefining the entire habilitation/rehabilitation system. Yet there has only been a single generation of severely disabled persons who have benefited from significant technological intervention. We are only now beginning to get a sense of the longer term issues that a comprehensive ongoing support system must address -such as: Where does the next adapted vehicle come from? How do you upgrade computer adaptations to remain competitive in the workforce as more sophisticated technology becomes available? What is a rehabilitation agency's role when former clients find they need financing for subsequent generations of equipment? 
The process of being an informed assistive technology consumer is a skill that technology users will need to maintain throughout their lives. They need to know how to identify personal needs for technology, how to review the equipment that exists, when to use technology services and related resources, and how to secure payment for the appropriate products and services. Because technology is an ongoing need, it is important for personnel in service delivery systems to help disabled people develop these consumer skills. It must be recognized that this type of informed consumer may be threatening to the program staff. Disabled consumers may become more knowledgeable than staff, and ask, even demand, that their expertise be acknowledged. However, if the "lifeskills counseling" aspects of developing these important skills can be recognized, perhaps the staff can be encouraged to see consumer technology skills inn the same light as resume writing and job search skills.

\section{Shared Opportunities for Training}

Some level of these kinds of consumer skills are needed by all decisionmakers working with the technology service delivery system, by professionals who are doing case management as well as by disabled consumers. Both groups need to learn to work with technology service providers and to maintain their participation in the process. This concept provides opportunities for developing training programs that can be used simultaneously by both groups. The skills that the counsellor develops can and should be shared with their clients. This is an area where educational activities do not need to be isolated or separately structured for either the professional or the consumer. These groups can and perhaps should learn these new skills together.

\section{Training the Young, Retraining the Old}

We traditionally think of adults as being the audience for employment. However, it is vital that technology, as it relates to employment, be consistently introduced to younger individuals with disabilities. The options that assistive technology can provide should become familiar to students with disabilities early on in regular, vocational and special education systems. Early introduction will help to realistically broaden the expectations related to career planning, educational requirements, etc. We cannot assume that disabled youngsters can aspire to and prepare for jobs that they do not realize can be made accessible to them.

Additionally, the older individual had traditionally been overlooked in the employment arena. This population includes both the aging individual who acquires a functional limitation later in life, and the disabled individual who is aging and may be experiencing an increase in functional limitations. There is technological support which can assist both of these groups. A primary focus should be placed on developing support systems which help the older individual remain in the work place. Most current programs in the U.S. are oriented toward returning the younger worker to employment. A broader vie is needed, and can be achieved if the potential is recognized and service delivery models are developed.

Technological support for the older individual is an area we should all be interested in, if for no other reason, for self-interest. We can point to the changing demo- 
graphics when we propose developing technology service delivery approaches for older individuals, but we can look in our own mirrors if we need a reason to make this issue a priority.

\section{Assistive Technology In Context}

Technology must be viewed in context. A piece of hardware is no the only way to solve a problem. It is one option. Others include: personal help, learning new skills, adapting the environments, redefining the problem. It would be unlikely that anyone but a "techie" would approach an everyday living problem by asking "What gadget can I get to solve my problem?" Most of us look at the range of possible options, determine the tradeoffs, the resources available, then make a decision.

\section{The Impact of the Independent Living / Disability Rights Movement}

Independent Living is not an alternative to being vocationally feasible. IL is the basic support services needed to live a self-directed life. Disabled individuals who are employed have also developed successful IL support systems, or they would never get to their jobs.

The Independent Living/Disability Rights Movement is having a profound impact on the field of rehabilitation in the U.S. Issues of self-determination, economic and community integration are recurrent themes. A 1986 Harris Survey documented an increased self-perception of disabled people as a minority group. There is no turning back as a self-help initiative develops into a civil rights paradigm. In 1990 The Americans with Disabilities Act(ADA) was signed into law. This landmark piece of disability policy is far from perfect, but it provides significant civil rights protection to all citizens with disabilities. An overview of this law is attached as Appendix A. With the shifts in disability policy that are occurring, it is obvious the new approaches must be considered in the way needs are defined and met, and in the way service outcomes are evaluated.

\section{The Need for Improved Outcome Measures}

The purpose of using technological solutions for employment should be to provide increased opportunities for participations in the labor market for an individual with a disability. However, U.S. programs which provide worker's compensation, social security disability insurance, and vocational rehabilitation are often constrained by outdated, uncoordinated and sometimes conflicting policies that make it difficult to realistically include interventions like assistive technology. The arbitrary nature and definitions of success found in systems like vocational rehabilitation, force agencies to take a very narrow and often skewed view of what they are trying to accomplish. There is pressure to produce high numbers of case closures, and little incentive or authority to provide ongoing support. More realistic mechanisms for evaluating and reporting successful outcomes are necessary if technological support is to be integrated into support systems for individuals with disabilities.

\section{Technology as a Metaphor for Ongoing Support Systems}

U.S. service delivery systems are geared to cure, closure, aging out, graduation, 
REIS'92

or some other finite fixed endpoint. In medical parlance, we operate in an " acute care" environment. Only recently has the concept of the ongoing nature of necessary supportive services emerged. Public policy has never been designed to adequately address this "long term care" environment. There have been struggles and confusion around areas which demonstrate the ongoing nature of services, e.g. "independent living" or "supported employment" services. They do not readily fit into outdated cure-oriented models.

Assistive technology does not fit the traditional closure-based model practiced in the social service/health/education models. None of the most basic underpinning supports for any individual -- environmental access in ones own environment, personal assistance/attendant care, and technological assistance -- fit into the current models. As a nation, we are struggling with this dilemma in the health care arena, but it is an endemic problem in all areas of human services.

Assistive technology provides a way to explain the concept of ongoing need. It may be easier for policy makers and implementors to understand the ongoing nature of community-based supportive services through the "metaphor" of technological support, because they are all used to replacing, etc. their own technology, while none of us who are not disabled give much thought to personal care of how our environments work for us. Technology is less alien than attendant care. Because it is easier to grasp the concepts of "continuity" around the issue of technology, it is logical that technology could serve as the starting point for clarifying pubic policy about the role of government in providing supportive services for needs that may change, but will probably last a lifetime. Technology represents a new way of thinking, one that more accurately reflects the independent living movement/disability rights perspective. When there is an integrated place for assistive technology in U.S. programs, the other social support systems will follow.

It may be difficult for you to understand how important the issue of ongoing support systems is in the U.S. We are struggling with ways to develop communitybased support systems for people with disabilities that are integrated and maintain consumer direction. Only very poor people in the U.S. are eligible for benefits from the existing social support network. We have a basic dilemma for individuals with disabilities. Existing policy makes it extremely difficult to escape unemployment and poverty, while still maintaining access to affordable support services. It is no surprise that almost $70 \%$ of Americans with disabilities are unemployed.

\section{The Unique Need of Integration Throughout the System}

If services to disabled people can be viewed as a patchwork quilt of woven cloth, it becomes more clear why it is so difficult to integrate technology into human services. A service like early intervention or supported employment can be viewed as a square of the quilt, one that had been overlooked and now needed to be added. The challenge was how to stitch the piece into the quilt, and much emphasis was placed on the joining needlework. Technology is, however, not just another square that needs to be stitched in. ( Nor are the other supportive services.) To be effective, technology must be viewed as a thread that needs to be woven throughout the entire patchwork quilt, it needs to be integrated. 
I do not know that we have a model for doing this. I cannot think of any other area where we had to take an existing system, and weave in a new set of fibers, across the board, for people of all ages. We have an opportunity to set the foundations for integrating public policy about community based supportive services here. It is not hard to imagine that we could use the model developed here to integrate personal assistance/attendant care services (used in home, at school, or at work) throughout the system; or to clarify environmental access at the level of the individual.

The assistive technology service delivery models we plan, develop, implement and support therefore have far greater significance than one might at first imagine. This may be one of the more concrete examples where real independent living concepts may be able to be turned from theory into concrete practice.

\section{Consumer Responsive Systems}

The language "consumer responsive" in the Technology Related Assistance for Individuals with Disabilities Act of 1988(P.L.100-407) is a good indication of the changes in the way we will be measuring the results of our services. Even though the new legislation does not define "consumer-responsive," or who should judge whether or not services are meeting that goal, it certainly does point to a measure for who judges the effectiveness of services. "Consumer-responsive" when viewed as a major criterion for outcome measurement tells me that we will need to be looking beyond any quantitative measures which are based on case closures. We will be evaluating impact. And more specifically, impact as viewed by the consumer.

\section{The Influence of Third Party Reimbursement Systems}

Although a great deal of assistive technology is bought and paid for out of pocket in the U.S., third party reimbursement still drives the system. Disabled adults are primarily affected by the various health insurance schemes (Medicare, Medicaid, private/group plan health insurance), compensatory insurance schemes (workers' compensation, long term disability, personal injury/liability, veterans' benefits), vocational rehabilitation schemes related to employment, and income subsidy schemes. There is an emerging set of financing mechanisms, some subsidized, some not, which an employed adult might use to purchase equipment; and there are always the schemes related to philanthropy/good will (voluntary health organizations, service clubs, special event fundraising, churches), though these are often more ready sources for children.

Having established that support systems need to be integrated and work together, if there is no mechanism for paying for the the parts of the support system that do not directly relate to employment, the agency trying to assist employment of the individual with a disability will either have to become the payor of last resort for devices that may be more properly considered medical, or will judge the individual unfeasible for employment because basic supports have not been available, or will witness the individual fail in an employment situation because of the absence of other necessary parts of an individualized support system.

The ADA protects individuals with disabilities from discrimination by employers of more than 15 employees. I fear that there will be attempts to thrust all responsibil- 


\section{REIS'92}

ity for jobsite technology onto the employer as part of their ADA responsibilities. It is predictable that unless additional remedies are found, employers will de facto discriminate against hiring individuals who need more costly accommodations. While we all quote the statistics about no cost and low cost accommodations, there are still many instances where costs are relatively high. Employers are much more likely to make the more expensive accommodations if there is a funding source to assist with the costs. If public funding subsidy is not available, in whole or in part, we risk turning employers into adversaries who feel compelled to protect their financial pockets. Since many American employers (as well as predicted job opportunities) are too small to be effected by $\mathrm{ADA}$, better incentives are needed to encourage hiring of employees with disabilities by small companies. Available funding for worksite accommodations, support for independent living support services (there are often not included in the health insurance policies of small employers), and a safety net for an employee with a disability would go a long way to encourage job opportunities in small businesses. Tax incentives have been developed, but other options need to be explored. It should be noted that the U.S. does not have an employment quota system. The quota approach would not be compatible with sentiment or philosophy of employers or disability rights activists. It may take us longer to integrate our workforce, but it will be worth it because qualified employees with disabilities will be of equal status and stature to their non-disabled counterparts, with all the rights and benefits of being a regular employee.

\section{THE ROLE OF TECHNOLOGY IN THE EMPLOYMENT OF PERSONS WITH DISABILITIES}

\section{Ideal Characteristics}

Based on the above issues, I want to reemphasize that we are learning that the best service delivery models for assistive technology and employment:

- extend beyond just technology used in the workplace;

- include daily living assistive technology which as a basic underpinning of routine activities directly influences and indirectly supports employment performance;

- include both high and low technology; includes mass market products, specialized products and custom adaptations;

- must be consumer responsive and reflect the ongoing nature of technological support;

- need to include individuals both younger and older than have traditionally been targeted by employment oriented services and outreach;

- may be a model for other types of ongoing supportive services;

- need to provide decision-making capability for consumers with disabilities and other paying agents;

- should be oriented to producing a benefit (which is valued by the person with a disability), not geared to selling hardware.

\section{The Current Situation: Are People Getting What They Need?}

In exploring the delivery system for assistive technology, to start with, we should ask: "Are people getting what they need? For most disabled adults, the "system" for getting needed technology does not work very well. There are serious problems related to gaps in information, funding, and coordination, and to an understanding of the benefits appropriately applied technology can provide. Current approaches are most likely to meet the needs of an adult whose needs are fairly straightforward, who 
has a sense of what he needs and how to go about getting it, and who has had some contact with the rehabilitation system.

Health care systems and the education model are beyond the scope of this paper. When just considering the traditional employment related systems in the U.S., Enders and Heumann (1988) describe the existing situation as follows:

Although the vocational rehabilitation (VR) system can provide services as young as age 16, and does provide post secondary educational and training opportunities, the primary emphasis is on adults. It is generally difficult to get services if one is over 55, though the agencies have mandate to serve older individuals.

Theoretically, the federal-state VR system can provide any technology that can be shown to be of value in preparing an individual for employment, or in maintaining that employment. In practice this is not always the case, and the interpretation of need is very narrow. The Rehabilitation Act Amendments of 1986 added additional emphasis on the provision of rehabilitation engineering services, but qualified it with the clause "where appropriate". There were no additional funds appropriated for this specifically mandated service; and yet these technology services are exempted from a similar benefits search. It is unlikely that the Rehabilitation Services Administration(RSA) will issue specific regulations interpreting this new section of the law. It is hoped that they will at least provide the state VR agencies with some guidelines for implementation. There is currently considerable confusion as to what the state VR agencies could and should be doing to meet this new obligation.

The VR system, with its focus on employment, has traditionally focused its attention on shorter term and/or time-limited types of interventions. However there is now an increased recognition of the importance of ongoing, coordinated support systems such as independent living and supported work. Technological support services and systems play an important role in these new trends. However there has only been a single generation of severely disabled persons who have benefitted from significant technological intervention. We are only now beginning to get a sense of the longer term issues that a comprehensive support system must address. There are many unanswered questions related to the rehabilitation agency's role when former clients find they need upgrading, replacement and financing for subsequent generations of equipment. And to the limits of typical coverage for assistive technology for clients in their active caseloads, eg should there be routine coverage for assistive technology that may be only used in the home, because without it the individual does not have the supportive base to stay competitively employed?

Other employment related service systems based on compensatory insurance schemes tend to take a broader and more long range view of the supportive technology their clients require. They will often provide the equipment and adaptations that are needed in the whole range of life activities, so they can make the earliest possible case settlement, and/or get the individual back to productive work and off their case roles. 
The system that provides for veterans with service-connected disabilities could be viewed as a compensatory system related to employment. This system bears further investigation because, although it has major flaws, for eligible beneficiaries, it seems to provide supportive technology and other services in a more comprehensive fashion. VA policy has tended to be that blind veterans would be provided with all necessary services and devices to overcome their handicap, and other disabled veterans could receive technologies deemed medically necessary. However the VA seems to define "medically necessary" much more broadly than most of the other systems. And they have had long standing coverage for home adaptations, adapted vehicles, etc. for veterans with service connected disabilities.

\section{Working Toward a More Appropriate System}

In the U.S. consumers have identified the next steps that are needed. These include: increasing awareness of the benefits and availability of technology; guidance in incorporating technology into existing programs; and training and interpretation for all participants involved about the role technological support can play.

There should at least be enough information, outreach and coordination to provide disabled adults with the expectation that appropriate technology and related services are available, that suitable solutions can be found, and that they have the right to assistive technology that is equivalent to an able bodied person's basic support systems.

The system should provide for the average disabled adult: easy ability to comprehensively identify personal needs for technology, to review the technology that exists in the field, and the ability to purchase equipment so that costs do not produce an inequitable hardship for the disabled person.

The resource allocation issue of whether or not assistive technology is a luxury or necessity is really an issue of equity: a disabled person should not have to pay more than an able bodied person to achieve comparable norms in functional abilities, lifeskills, or lifestyles. The self reliant American approach steers us to take care of ourselves/our families. However as our lifespans increase, our ability to save the lives of infants and traumatically injured improves, we are as a nation being faced with the recognition that the individual/family may need to bears some extra costs, but that those costs should not be catastrophic. Our tax codes reflect this philosophy, e.g. only after we have spent $7.5 \%$ of our taxable income on medical expenses can we deduct any additional expenditures.

When looking at setting up a system for assessment, funding and maintenance on technology it is essential that we look at training consumers as well as health care professionals regarding how to use, order, pay for and maintain the equipment, as well as knowing how and when to re-evaluate its effectiveness and replace it when necessary.

\section{ASSISTIVE TECHNOLOGY SERVICE DELIVERY}


One of the most interesting features of the Disability Technology Business in the U.S. is the variety of permutations that has emerged. Rarely do we find an exemplary program that is purely one thing or another, or one that employs only one type of professional. These hybrids make it confusing to categorize the field. This difficulty of fitting technology services into neat boxes, however, demonstrates well the widely pervasive range of technology need and the demand for services. When exemplary models are examined, one also sees creatively and entrepreneurship that bodes well for the flexibility and viability of the field.

The field of technology services is broad, and is emerging from several different arenas, responding to different demands and varying needs. Some of the practitioners may not have yet recognized that they all belong under the same broad umbrella of Assistive Technology Services. Some programs have emerged from the traditional field of prosthetics/orthotics, others from the durable medical equipment industry. Interest in job site modification spurred some, others developed along with the advances in technology, e.g., augmentative communication, or specialized vehicles. Some have a strong architectural/design flavor, others respond to certain populations, such as farmers or children. Some are for profit, others are in the public sector. Some are heavily oriented to information provision, while others primarily sell quality assurance and case review.

What we are now generically calling "assistive technology services" have been provided under various other names for many years. The practice may not be new, but the necessity for a conceptual change is. What has changed significantly in the past several years is the nature of the technology available for helping persons with disabilities and the environment in which rehabilitation services are provided. Engineering has been and continues to be one of the essential component of rehabilitation technology, both in research and development and in service delivery.

Increased attention to the field of assistive technology devices and services has also been spurred by provisions in public laws including the Rehabilitation Act Amendments of 1986 and particularly section 508 which provides incentives for mass market manufacturers to incorporate accessibility features in all of their electronic office equipment; the Technology Related Assistance for Individuals with Disabilities Act of 1988 with its emphasis on consumer responsiveness and local systems change, the Older Americans Act Amendments, the Fair Housing Act, and of course, the Americans with Disabilities Act of 1990 with its civil rights protections in employment, telecommunications, public accommodations, and public services. (ADA does have some serious flaws, e.g. it does not cover private dwellings, health insurance, etc. It could be emulated in spirit, but no attempt should be made to model other legislation from it as it word for word.)

\section{Components of an Assistive Technology Delivery System}

The increased complexity, variety, and potential benefits of technological support demand that we learn to take advantage of methods that will ensure we are getting the most value from available resources. Specialized technology for people with disabilities has been available from prosthetists, orthotists, occupational thera- 
REIS'92

pists, physical therapists, speech pathologists, orthopedists, durable medical equipment (DME) suppliers, rehabilitation engineers, rehabilitation technologists, van modifiers and adapted driving specialists, wheelchair repair shops, rehabilitation engineering centers, hospitals, clinics, workshops, special education programs, charitable groups, pharmacies, low vision clinics, etc. However, technology services may or may not have been provided with the equipment.

The following variables were identified in discussions at a state of the art symposium on assistive technology service delivery, as being essential components of any comprehensive assistive technology service delivery program:

- Knowledgeably trained, available service providers,

- Consumers who understand the benefits technology offers, and know where to find services,

- Professionals who understand the benefits technology offers their clients and who can make appropriate referrals,

- Product availability,

- Availability of technological services,

- Financial resources availability to pay for products and services, and

- Information that links these other components together.

In the first chapter of Rehabilitation Technology Services Delivery: A Practical Guide, (available from RESNA, 1101 Conneticut Avenue, NW, Suite 700, Washington, D.C. 20036, USA) seven U.S. models of services delivery in assistive technology are described. The taxonomy is based on the administrative setting of service delivery program. Each of the seven models provides only a portion of the service delivery in the overall system, and depends on the others to form one comprehensive service delivery matrix. You are referred to this document for a fuller discussion of not just models of U.S. assistive technology service delivery, but also to a good introduction to the practical aspects of assistive technology service delivery in the U.S.

\section{CONCLUSION}

Policies guiding the development and distribution of assistive technology and related services may differ between countries. But we still have a lot of common ground for sharing information and strategies about effective approaches. There is much to be learned about the best methods for assessing technological needs, in matching identified needs to the most appropriate devices, in training in use of devices, in good ways to maintain and repair equipment, in protocols for equipment evaluation, in developing standards for interfaces and connectivity. We all need to do a better job in ensuring that people with disabilities are an integral part of the process, and that we are really listening to what they say they need. People with disabilities need to become co-designers, and to have more control over their assistive technology.

We can also work together on promoting universal design and lifespan product design. When mass market commercial products are designed with accessibility features built in, there will be less need for customized special products. Realistically, most of the significant advances in daily living aids for people with disabilities have been mass market products and services designed for convenience. BSR environment control units, automatic garage door openers, microwave ovens, speaker phones, bidet type toilet seats, waterbeds, personal computers, edible TV dinners and other convenience foods, food processors, oven rack pullers, automatic dishwashers, home 
security systems, Niagara beds, velcro shoe closures, jogging suits as acceptable streetwear, vibrators, hot tubs, hand held shower massage units, electric toothbrushes, electric can openers, remote controls for almost everything, and on and on. Office equipment, programmable phones and other electronic gadgets, electric staplers, ergonomically correct chairs, and particularly computers have all added a whole new layer of transparent access at reasonable prices. The best way to develop accessible commercial products is to increase incentives and the awareness of product design professionals. As the world becomes a global marketplace, we can all work together to promote awareness and incentives. What better incentive could manufacturers have than consumers who can readily purchase their products? Independent Living philosophy is based on principles, we can start with specialized assistive technology, and move toward universal design, hospitable environment, and real integration.

Alexandra Enders, OTR/L

Rural Institute on Disabilities

The University of Montana 59812, U.S.A.

406/243-5467 
Appendix A

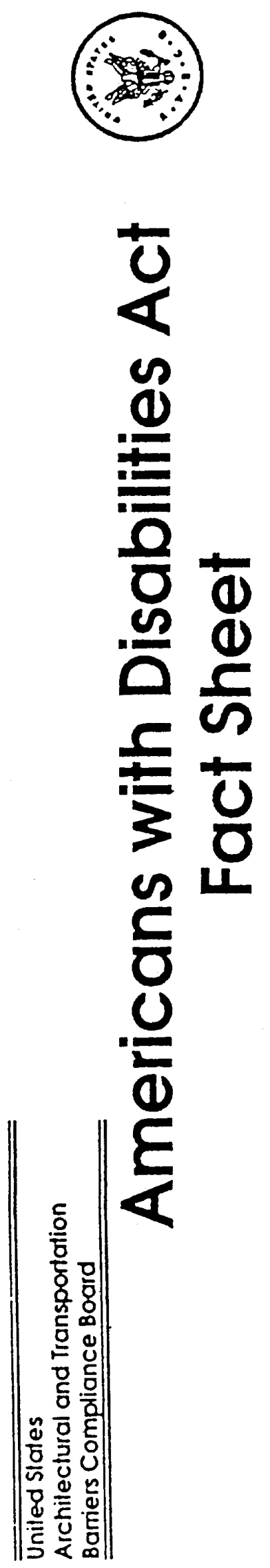

\begin{tabular}{|c|c|c|c|}
\hline 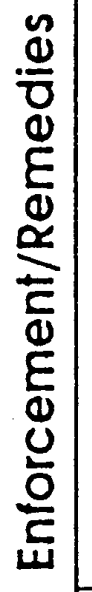 & 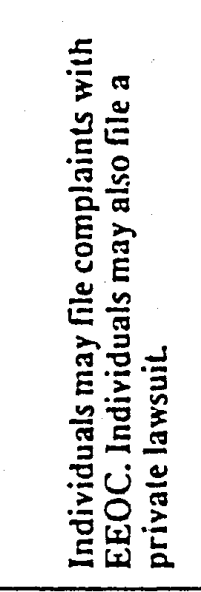 & 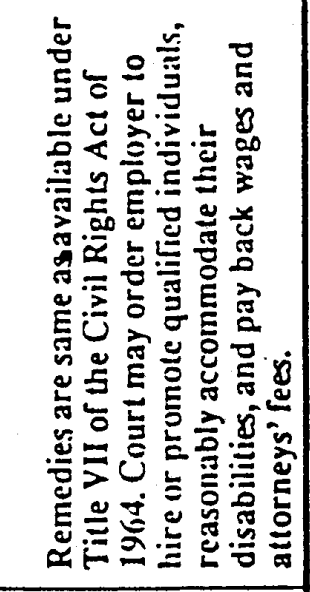 & 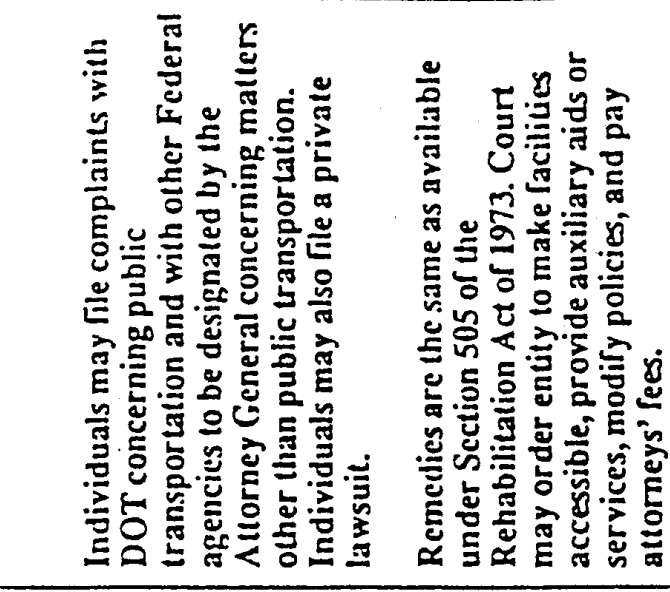 \\
\hline $\begin{array}{l}\stackrel{n}{c} \\
\stackrel{0}{0} \\
\frac{0}{3} \\
\stackrel{0}{d} \\
\underset{\alpha}{\alpha}\end{array}$ & 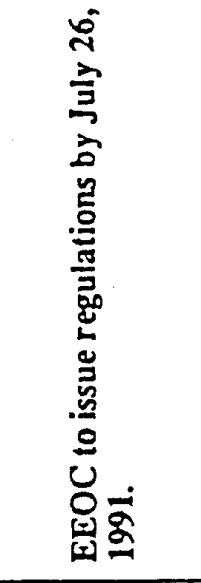 & & 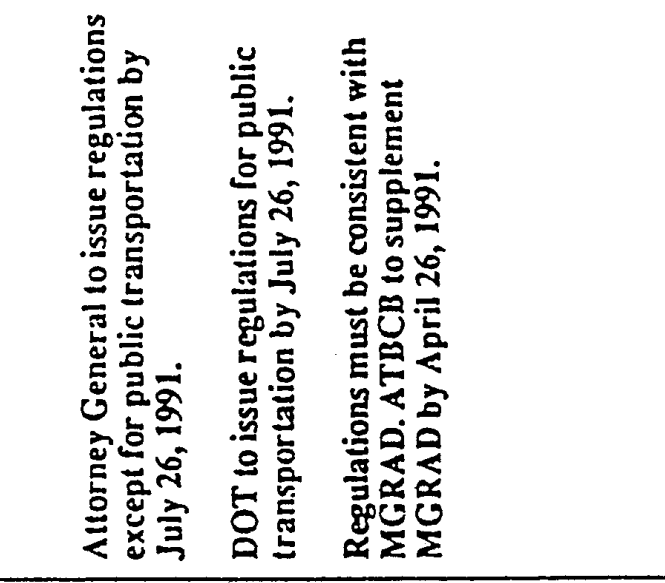 \\
\hline 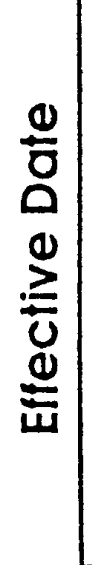 & 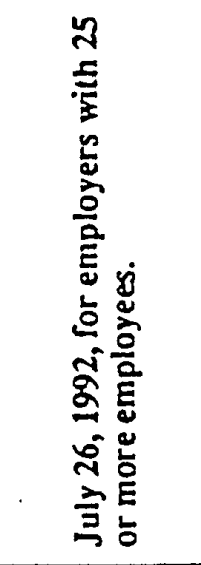 & 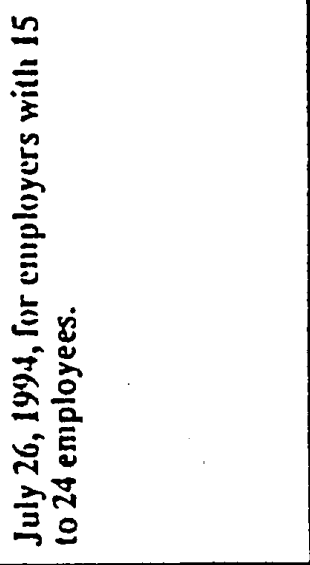 & 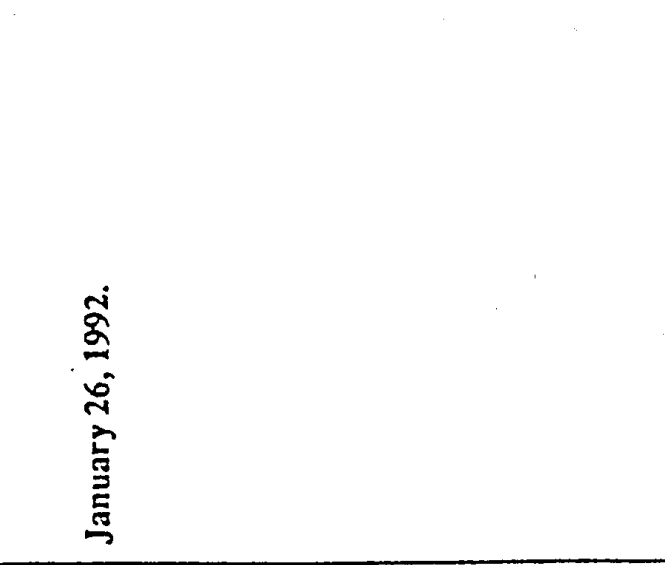 \\
\hline$\stackrel{\Phi}{E}$ & 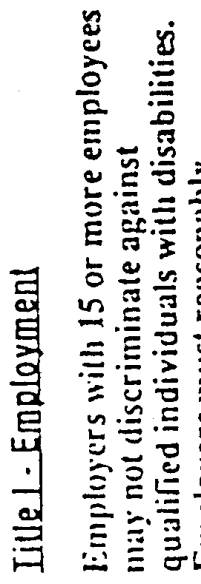 & 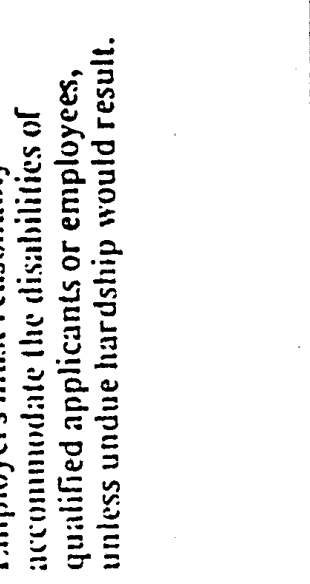 & 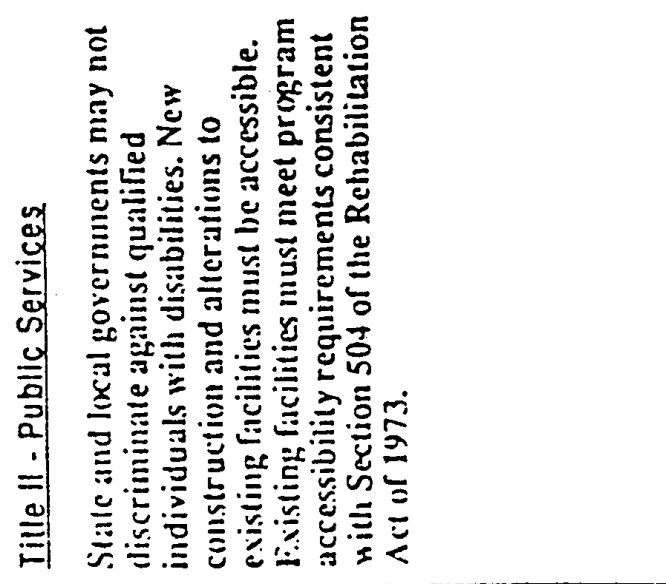 \\
\hline
\end{tabular}




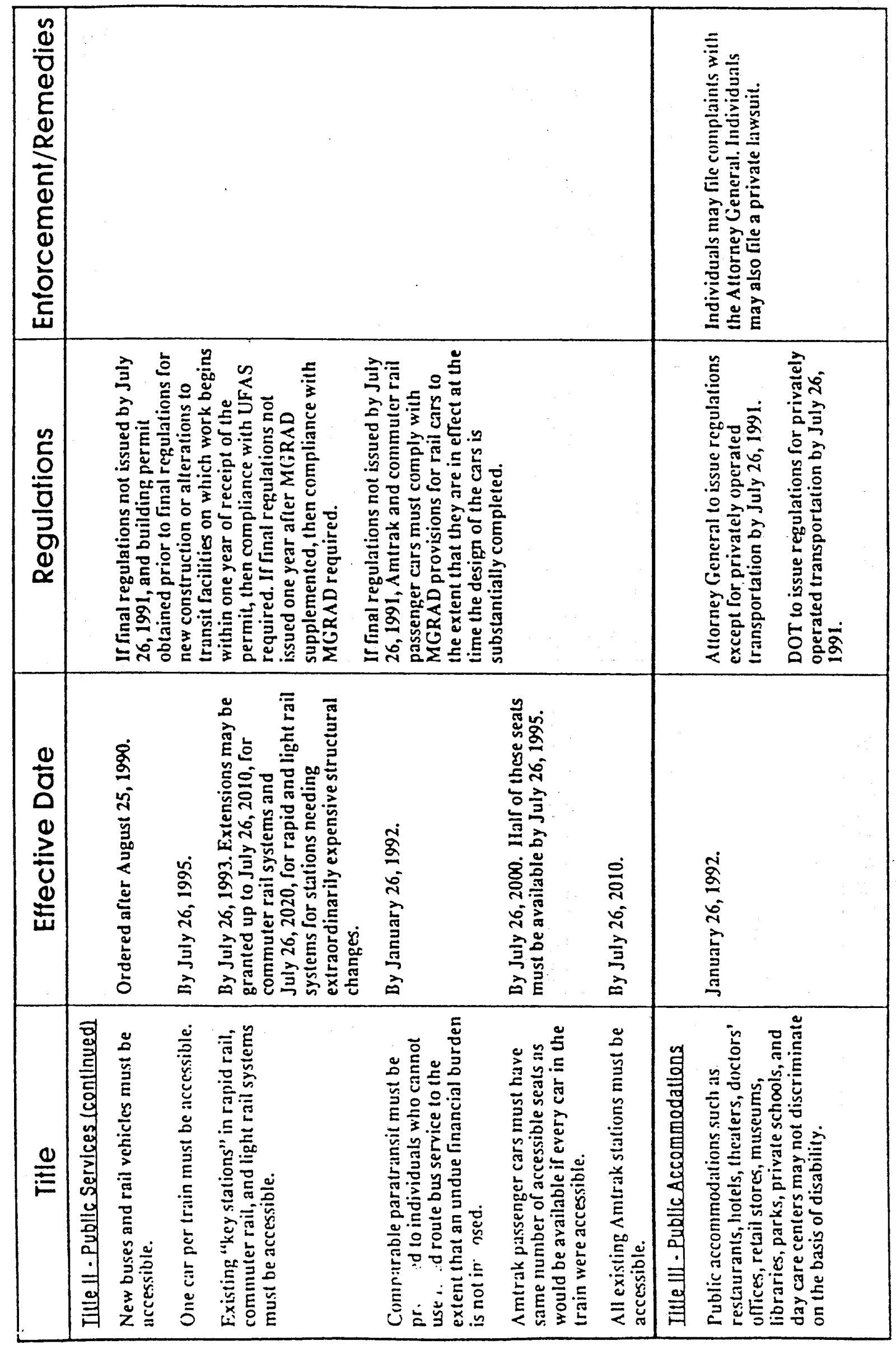




\begin{tabular}{|c|c|c|c|c|c|}
\hline 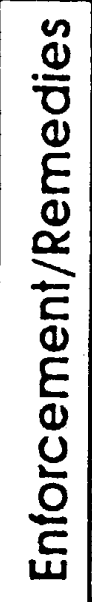 & & 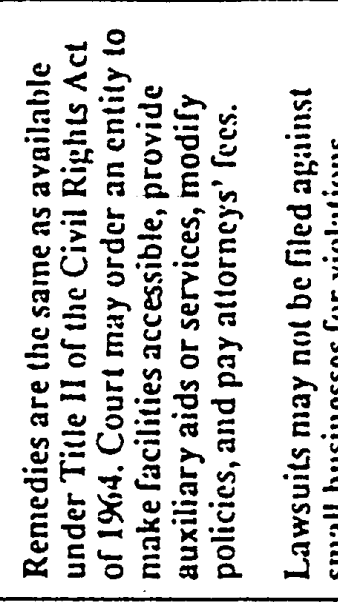 & 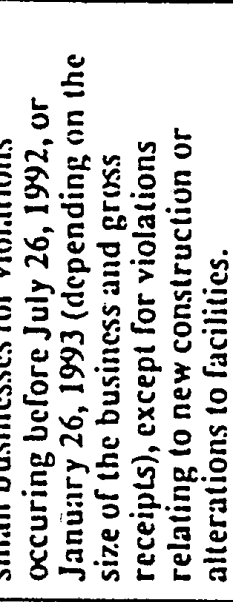 & & 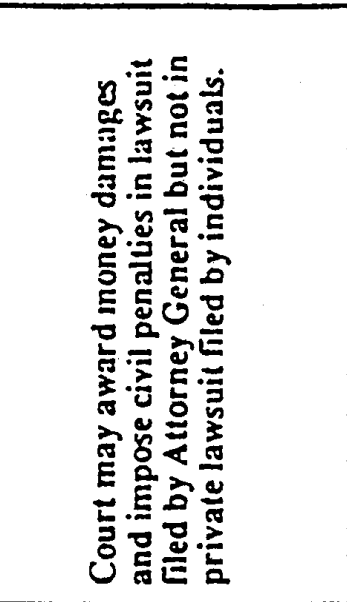 \\
\hline 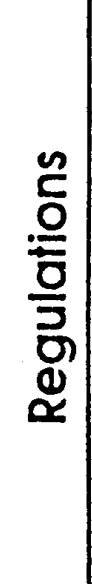 & & 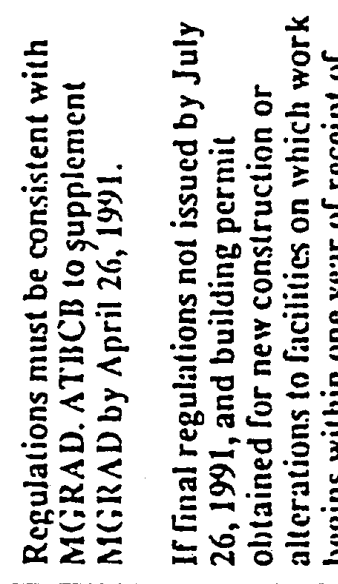 & 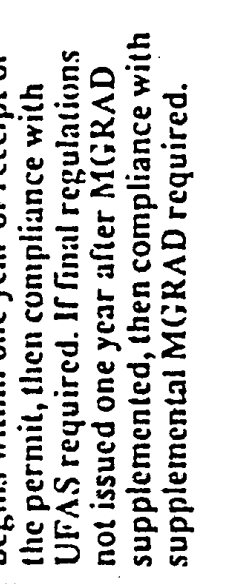 & 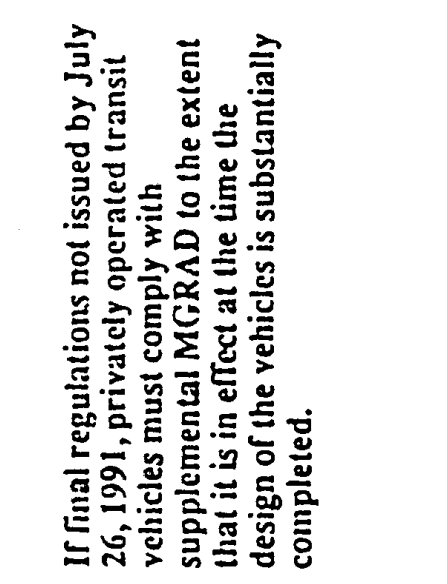 & 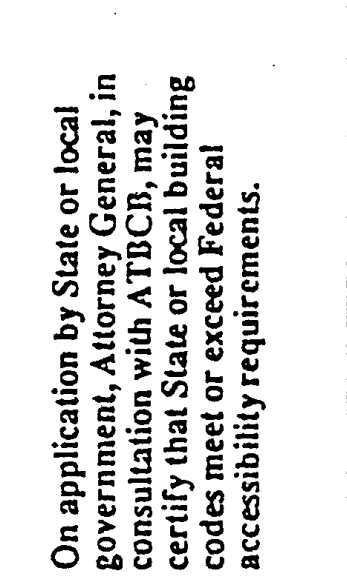 \\
\hline 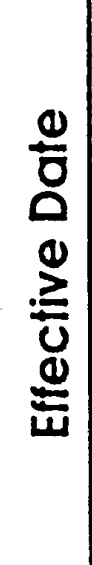 & & 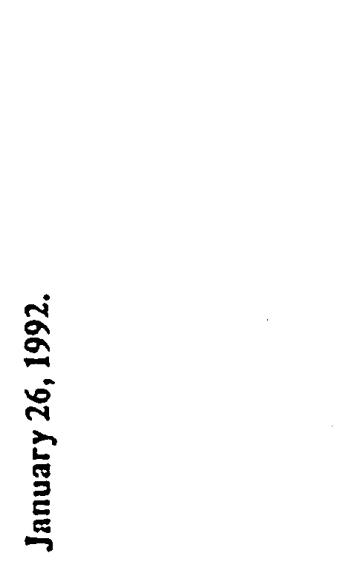 & 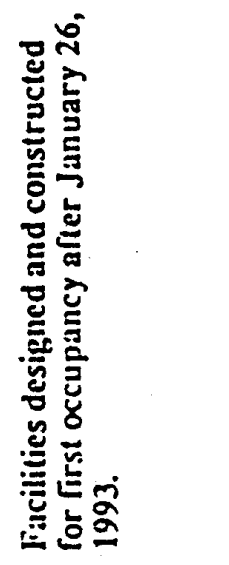 & 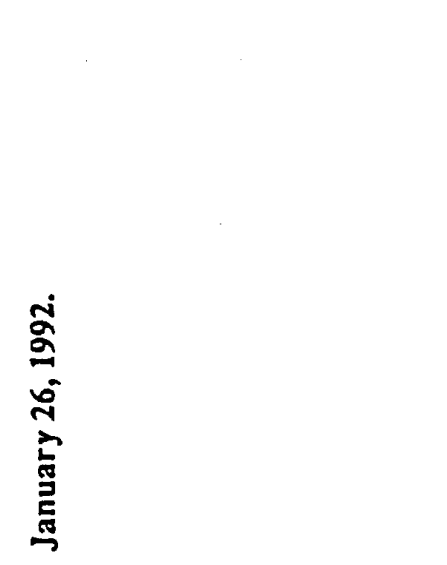 & \\
\hline$\stackrel{\underline{D}}{E}$ & 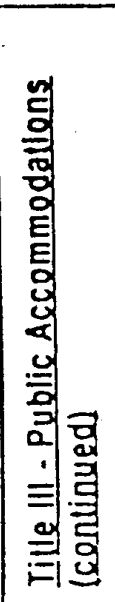 & 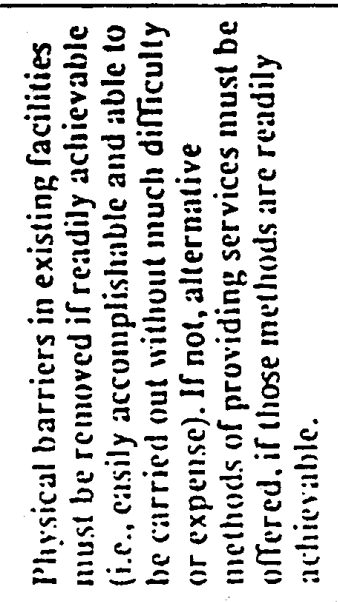 & 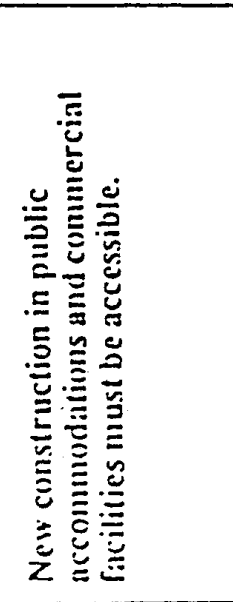 & 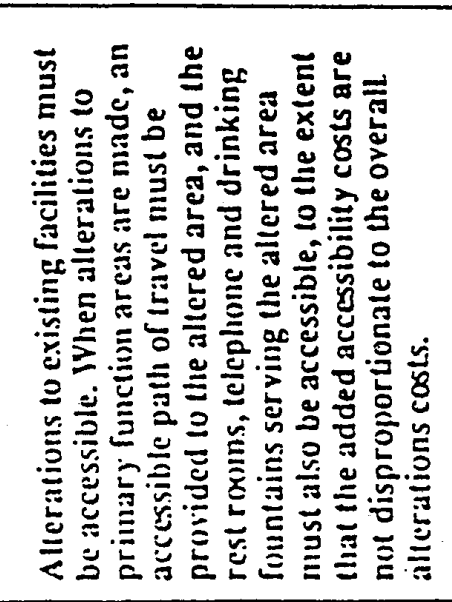 & 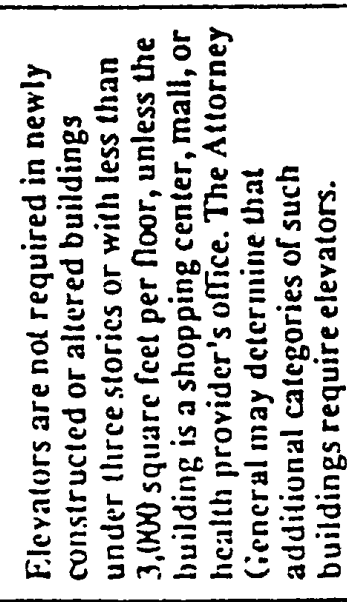 \\
\hline
\end{tabular}




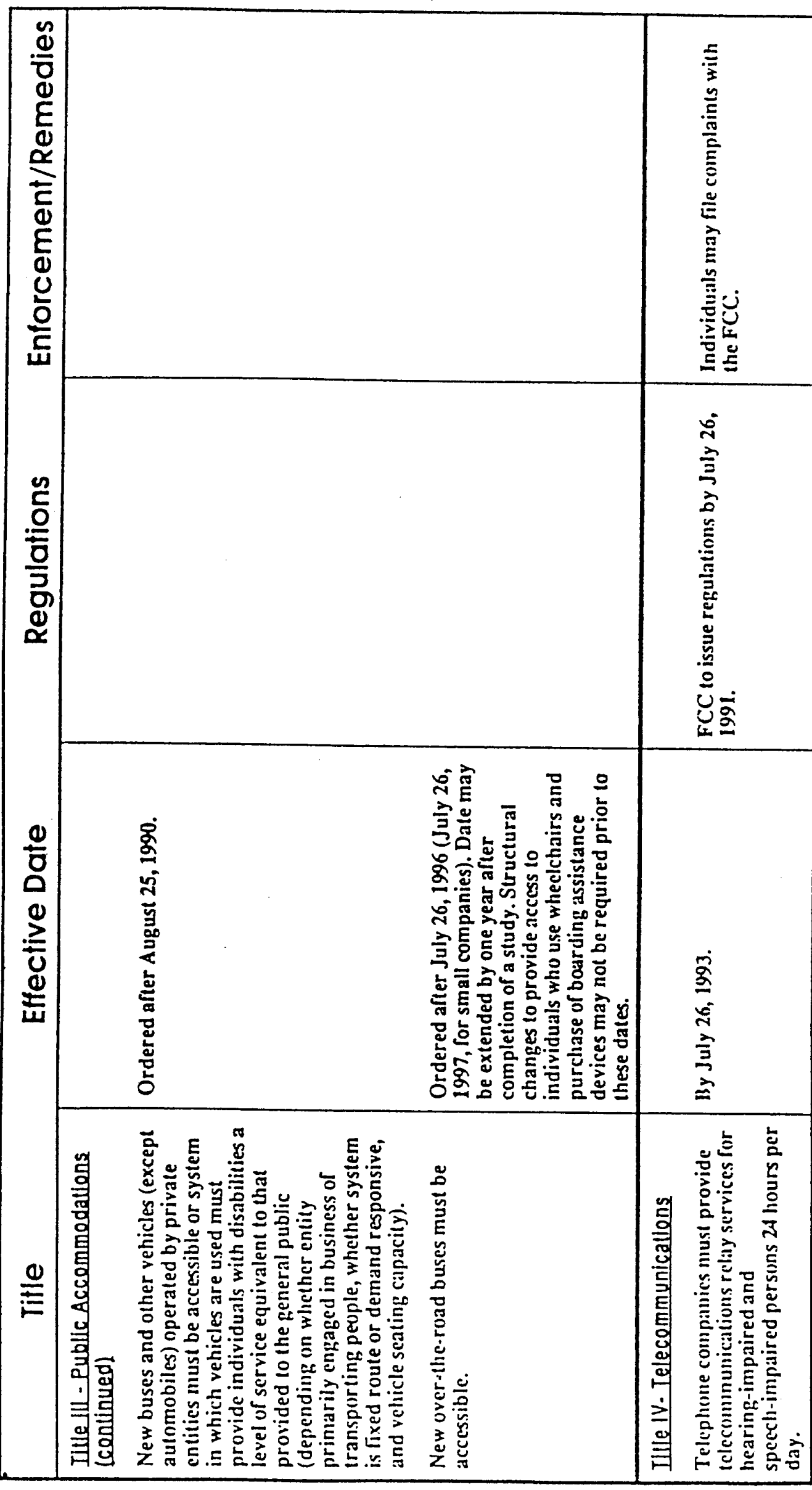

